\title{
Quantitative Determination of thymoquinone in Nigella Sativa and its nano formulation using validated stability indicating HPTLC densiometric method
}

\author{
Mohamad Taleuzzaman ${ }^{1}$, Syed Sarim Imam² and *Sadaf Jamal Gilani ${ }^{1}$ \\ ${ }^{1}$ Department of Pharmaceutical Chemistry, Glocal School of Pharmacy, Glocal University, Saharanpur -247121. (UP), India \\ ${ }^{2}$ Department of Pharmaceutics, Glocal School of Pharmacy, Glocal University, Saharanpur -247121. (UP), India
}

\begin{abstract}
An accurate and stability indicating high-performance thin layer chromatographic method (HPTLC) was developed and validated for the quantification of thymoquinone (TQ) as per the ICH guidelines. The analysis was carried out on the aluminum plate using nhexane: ethyl acetate: methanol $(7: 2: 1 \mathrm{v} / \mathrm{v} / \mathrm{v})$ as the mobile phase and the densitometric determination was carried out by TLC scanner (CAMAG) at $254 \mathrm{~nm}$. The developed method was validated for different parameters like linearity, precision, recovery, robustness, and stressed stability study. The developed analytical method was found to be linear in the concentration range of 75-500 $\mathrm{ng}^{\mathrm{band}} \mathrm{d}^{-1}$ with regression value closer to unity $\left(r^{2}=0.997\right)$. The developed system was found to give compact spots for thymoquinone $\left(R_{\mathrm{f}} 0.77\right)$ with the limit of detection and limit of quantification (18 and $54 \mathrm{ng}$ band $\left.^{-1}\right)$ respectively. Further, the study showed accuracy, precision and repeatability were all within the required limits. The stress degradation study of TQ showed well separated degraded peak from the pure thymoquinone. The mean recoveries measured at three concentrations were more than $95 \%$ with RSD $\leq 3 \%$. The method has been successfully applied in the analysis and routine quality control of herbal material and formulations containing TQ.
\end{abstract}

Key Words: Nigella Sativa, thymoquinone, HPTLC, validation, stress degradation, Nano formulation.

\section{INTRODUCTION}

Nigella sativa Linn. (Ranunculaceae) very often known as black seed or black cumin, is an herbaceous plant, mostly found in the middle east, Central Europe, and Western Asia. It is broadly used in indigenous system of medicine for treatment of numerous disorders for over 2000 years (Alam et al., 2013). Thymoquinone (TQ, Figure 1) is the precious constituent of the volatile oil of Nigella Sativa seeds, has shown vital medicinal properties, and has long been used in traditional and folk medicines (Ragheb et al., 2009). The main bioactive constituent of Nigella Sativa is TQ and various biological activities have been reported in different research (Akhtar et al., 2014; Sayeed et al., 2017). TQ belongs to the family of monocyclic monoterpenes, having the molecular formula $\left(\mathrm{C}_{10} \mathrm{H}_{12} \mathrm{O}_{2}\right)$ and IUPAC name 2-methyl-5-propane-2-yl-cyclohexane-2, 5-diene1,4-dione phenol. Most properties of the whole seeds or their extracts are mainly attributed to the presence of quinone constituents in the volatile oil and the most abundant component found is thymoquinone (about 27$57 \%$ ) (Ali et al., 2003). Other pharmacologically active constituents, present were dithymoquinone, thymohydroquinone and thymol in low content (Ghosheh et al., 1999).

The most preferred analytical tool for fingerprints and quantification of marker compounds in herbal drugs used is HPTLC. This technique has shown accuracy, sensitivity, suitability for high-throughput screening, reliability in the quantification of analytes from nanogram to microgram levels (Tayade et al., 2007; Kaur et al., 2008). It has several advantages in comparison to high-

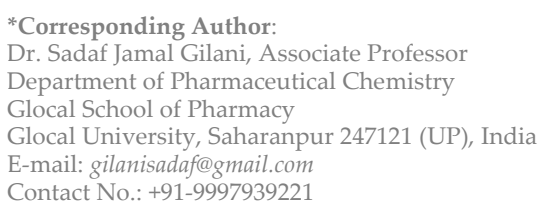

performance liquid chromatography (HPLC), it can analyze several samples, use the small quantity of mobile phase, as well as it facilitates repeated detection (scanning) of the chromatogram, analyze different kinds of samples, which reduces the time, and cost of analysis (Kaur et al., 2008) (Dixit et al., 2008). Although several methods such as thin-layer chromatography (AbouBasha et al., 1995) gas chromatography (Houghton et al., 1995). HPLC (Ghosheh et al., 1999). HPTLC (Michelitsch et al., 2003). and differential pulse polarography (Reelma et al., 2011) have been used to quantify the TQ in black seed oil. But till now not a single stress induced HPTLC method was developed to quantify TQ.

The International Council for Harmonisation (ICH) guideline entitled Stability Testing of New Drug Substances and products requires the stress testing to be carried out to elucidate the inherent stability characteristics of the active substance (Stolarczyk et al., 2010). There are different stability parameters (oxidation, hydrolytic and the photolytic) used for the stress stability studies. An ideal stability- indicating method is one that quantifies the standard drug alone and also resolves its degradation products (Zammataro et al., 2010). The basic acceptance criteria for evaluation of validation experiments based on practical experience for planar chromatographical procedures, which may be used at different levels either in qualitative identity testing, assays, semi-quantitative limit tests or quantitative determination of impurities (Bakshi et al., 2011). Form this approach, the aim of the present study to develop and optimize a simple and selective HPTLC method for the quantification of TQ for purity assessment in bulk as well as in in-house developed nanoformulation. The proposed method was validated as per ICH guidelines (Ranganathan et al., 2002; Sethi et al., 1996) and its updated international convention (ICH, Q2A, 1994). 


\section{MATERIALS AND METHODS}

\section{Materials}

Pure Thymoquinone and Mature seed powder of Nigella Sativa were purchased from Sigma Aldrich, Mumbai and from Sunpure extract private Ltd. (Delhi) respectively. Precoated silica gel 60 F254 HPTLC plates were purchased from E. Merck, Germany. All the solvents used were of chromatography grade and other chemicals used were of analytical reagent $(\mathrm{AR})$ grade. Water was purified by a Milli-Q system (Millipore Corporation, Bedford, MA, USA).

\section{Methods \\ HPTLC instrumentation and condition.}

The samples were spotted in the form of bands of width 6 $\mathrm{mm}$ with a Camagmicrolitre syringe on precoated silica gel aluminum plate $60 \mathrm{~F}-254,(20 \mathrm{~cm} \times 10 \mathrm{~cm}$ with $250 \mu \mathrm{m}$ thickness; E. Merck, Darmstadt, Germany, supplied by Anchrom Technologists, Mumbai). Methanol was used to wash the plates and activated at $60^{\circ} \mathrm{C}$ for $5 \mathrm{~min}$ prior to the study. A constant sample application with the rate of 140 $\mathrm{nL} \mathrm{s}-1$ was employed and space between two bands was 6 $\mathrm{mm}$ maintained. The slit dimension was kept at $5 \mathrm{~mm} \times 0.45$ $\mathrm{mm}$ and $20 \mathrm{~mm} / \mathrm{s}$ scanning speed was employed. The monochromatic bandwidth was set at $20 \mathrm{~nm}$, each track was scanned thrice and a baseline correction was used. The optimized mobile phase composition $(20 \mathrm{~mL})$ consisted nhexane: ethyl acetate: methanol $(7: 2: 1 \mathrm{v} / \mathrm{v} / \mathrm{v})$ was used for the analysis. Linear ascending development was carried out in $20 \mathrm{~cm} \times 10 \mathrm{~cm}$ twin trough pre-saturated glass chamber (Camag, Muttenz, Switzerland). The HPTLC plate development was carried out for twice with the same mobile phase to get high resolution. The optimized chamber saturation time for mobile phase was $30 \mathrm{~min}$ at room temperature $\left(25 \pm 2^{\circ} \mathrm{C}\right)$ at the relative humidity of $60 \pm 5 \%$. Densitometric scanning was performed on Camag TLC scanner III in the reflectance-absorbance mode at $254 \mathrm{~nm}$ and operated by WinCATS ${ }^{\circledR}$ software (Version 1.2.0).

Preparation of standard and quality control (QC) samples A standard stock solution of TQ $(10 \mathrm{mg} / \mathrm{mL})$ was prepared in methanol and further dilution of the standard was done in the concentration range of 0.1 to $1.0 \mathrm{mg} / \mathrm{mL}$. The calibration of TQ standard solution (1-10 $\mu \mathrm{L})$ was applied to an HPTLC plate to furnish amounts in the range 75-500 ng band $^{-1}$. The data of peak area vs. drug concentration were treated by linear least square regression analysis. QC samples as low, medium and high at the concentration level of 250, 350 and 400 ng band $^{-1}$ were taken to carry out validation of the method. Three replications of each calibration standard were performed $(n=3)$.

\section{Extraction process}

The weighed quantity of NS seed powder was packed in a muslin cloth and kept in the beaker containing sufficient quantity of methanol for $72 \mathrm{hrs}$. Thereafter the methanolic extracts were filtered through Whatman paper no. 42 and the resultant filtrates were concentrated under reduced pressure using the rotary evaporator to yield a concentrated mass which was labeled as meth-NS and preserved in airtight amber colored glass container at $4^{\circ} \mathrm{C}$ until use. The fingerprinting of methanolic TQ extract was enact by spotting $10 \mu \mathrm{L}$ of suitably diluted sample solution on an HPTLC plate.

\section{Method validation}

The developed method was validated as per ICH guidelines for linearity range, precision, accuracy as recovery,<smiles>CC1=CC(=O)C(C(C)C)=CC1=O</smiles>

Figure 1: Chemical structure of Thymoquinone.

robustness, limits of detection (LOD), limits of quantification (LOQ) and stability study (Ali et al., 2016; Mittal et al., 2015).

\section{Precision}

The inter-day precision study was done by repeating the study on same day whereas in intraday assay the same study was repeated for three different days. In both, the study, precision of the developed method was evaluated by performing replicate analyses $(n=6)$ of QC samples at low ( $250 \mathrm{ng}^{\text {band }}{ }^{-1}$ ), medium (350 ng band ${ }^{-1}$ ) and high levels $\left(400 \mathrm{ng} \mathrm{band}^{-1}\right)$. The result of precision was expressed as the percent recovery with the coefficient of variation of measured concentrations for each level.

\section{Accuracy}

The accuracy was determined by standard additions method at three different levels, i.e., by multiple level recovery studies. The recovery studies were performed with the addition of extra percentage level of 50,100 and $150 \%$ from the initial level (Ali et al., 2016). It was performed by application of test sample $(n=6)$ of known concentrations of TQ that had been prepared from stock solutions. The percent recovery was calculated using regression equation at different levels in the sample.

\section{Limit of detection (LOD) and quantification (LOQ)}

The limit of detection and limit of quantification are applied for the determination of low levels of the compound in sample matrices and is used particularly for the determination of impurities and degradation product in the quantitative assay. To estimate the limits of detection (LOD) and quantification (LOQ), blank methanol was applied $(n=6)$ and the standard deviation $(\sigma)$ of the analytical response was determined. The LOD and LOQ values were calculated from the calibration curves as $\mathrm{k \sigma} / \mathrm{b}$ where $\mathrm{k}=3$ for LOD and 10 for LOQ, $\sigma$ is the standard deviation of the intercept and $b$ is the slope of the calibration curve.

\section{Robustness}

Robustness was determined by introducing small changes in the different parameters such as mobile phase composition, mobile phase saturation time, and mobile phase volume and their effects on the results were examined. The study was performed in triplicate at $350 \mathrm{ng}^{\text {band }}{ }^{-1}$ and the effects of changes were examined on the results of peak areas and $R_{f}$ value. The mobile phase composition n-hexane: ethyl acetate: methanol in different proportions (7.5:1.8:0.7 and 6.8:2.1:1.1 v/v/v) and mobile phase volume $(13,17$ and $15 \mathrm{ml}$ ) and duration of saturation (10,20 and $30 \mathrm{~min}$ ) were investigated. Further, the plates were prewashed with methanol and activated at $60 \pm 5^{\circ} \mathrm{C}$ for 2,5 and 7 minutes. 


\section{Specificity}

The specificity of the method was ascertained by analyzing standard drug and sample. The spot for TQ in the sample was confirmed by comparing the RF and spectra of the spot with that of the standard. The peak purity of TQ was assessed by comparing the spectra at three different levels, i.e., peak start (S), peak apex $(\mathrm{M})$ and peak end $(\mathrm{E})$ positions of the spot.

\section{Analysis of TQ from Developed nano Formulation}

The validated developed method was applied to the quantification of TQ in-house developed TQ loaded nanoformulation. The estimation of the contents of TQ in nanoformulation, $5 \mathrm{~mL}$ of nanoformulation was extracted with $10 \mathrm{~mL}$ methanol. To ensure complete extraction of the drug, it was sonicated for $30 \mathrm{~min}$ and centrifuged at 3000 rpm for $10 \mathrm{~min}$. The supernatant of each sample was suitably diluted to give desired concentration (400 ng spot $\left.{ }^{-1}\right)$. After that, it was applied on TLC plate followed by the development. The result of the peak area obtained corresponding to TQ was used for quantification in samples using regression equation. The results of the triplicate analysis were expressed as an average amount of TQ in \% $\mathrm{w} / \mathrm{w}$. The possibilities of excipient interference in the analysis were studied.

\section{Stability studies}

The stress testing of the drug substance can help identify the likely degradation products, the stability of the molecule and also validate the stability and specificity of the analytical procedures. The degradation studies were carried out as per by subjecting the standard thymoquinone sample to oxidation, wet heat, dry heat and photo-degradation to evaluate the stability indicating properties of the developed HPTLC method.

\section{Hydrogen peroxide-induced degradation}

To $25 \mathrm{ml}$ of a methanolic stock solution of thymoquinone, $10 \mathrm{ml}$ of $50 \% \mathrm{w} / \mathrm{v}$ hydrogen peroxide were added. The solution was heated in boiling water bath for $15 \mathrm{~min}$ to remove completely the excess of hydrogen peroxide and then refluxed for $2 \mathrm{~h}$ at $70^{\circ} \mathrm{C}$. The resultant solution $(200 \mathrm{ng}$ band $^{-1}$ ) was applied to TLC plate and the chromatograms were run for the analysis as described above.

\section{Dry heat and wet heat degradation}

The standard drug was placed in the oven at $100^{\circ} \mathrm{C}$ for 7 days to study dry heat degradation, and the stock solution was refluxed for $12 \mathrm{~h}$ on boiling water bath for wet heat degradation. The resultant solution (200 $\mathrm{ng}$ band $\left.^{-1}\right)$ was applied on TLC plate. Further, the HPTLC study was performed and the chromatograms were run for the analysis.

\section{Photochemical and UV degradation}

The photochemical stability of the thymoquinone was also studied by exposing the stock solution $\left(250 \mathrm{~g} \mathrm{ml}^{-1}\right)$ to direct sunlight for 3 days on a wooden plank and kept on the terrace. The thymoquinone solution was also exposed to UV radiation for 15 days in UV stability chamber. One microlitre (200 ng band $\left.{ }^{-1}\right)$ from each sample was applied on TLC plate and chromatograms were run as described above.

\section{RESULTS AND DISCUSSION}

\section{Mobile phase optimization}

There are different solvent systems were tried for the separation of thymoquinone on the TLC plates. Initially, the different solvent system used as the solvent system to get a high-resolution peak, and get better peak resolution. The
Table 1: Linear regression analysis data for the developed HPTLC method of Thymoquinone.

\begin{tabular}{|c|c|}
\hline Parameter & Values \\
\hline$R_{\mathrm{F}}$ & 0.77 \\
\hline Linearity range (ng band ${ }^{-1}$ ) & $75-500$ \\
\hline Regression equation & $16.58 x-224.2$ \\
\hline Correlation coefficient $\left(r^{2}\right)$ & 0.997 \\
\hline Slope \pm SD & $0.0068 \pm 0.0067$ \\
\hline LOD & 18 ng band $^{-1}$ \\
\hline LOQ & 54 ng band $^{-1}$ \\
\hline Recovery (\%) & $99.15 \pm 1.44$ \\
\hline Robustness & Robust \\
\hline Specificity & Specific \\
\hline
\end{tabular}

optimized mobile phase system was found n-Hexane: ethyl acetate: methanol in the ratio of $(7: 2: 1 \mathrm{v} / \mathrm{v} / \mathrm{v})$. The $\mathrm{R}_{\mathrm{f}}$ value found with this mobile phase composition was 0.77 for all the samples shown in Figure ( $2 \& 3)$. The resolution between spots of standard and depredates appeared better, when the TLC plates were pretreated with methanol, activated at $60^{\circ} \mathrm{C}$ for $30 \mathrm{~min}$, and were saturated with conc. ammonia vapors for $30 \mathrm{~min}$ in TLC chamber prior to application. It was required to eliminate the edge effect and to avoid unequal solvent evaporation losses from the developing plate that can lead to various types of random behavior usually resulting in lack of reproducibility in $R_{f}$ values. So the attempt has been taken to develop and validate a cost-effective simple and robust HPTLC technique to quantify thymoquinone in the methanolic extract of $\mathrm{Ni}$ gella Sativa. The methanolic extract peak of thymoquinone was well resolved at $\mathrm{R}_{\mathrm{f}}$ value 0.77 depicted in Figure 3 . The developed method was found to be quite selective with good baseline resolution of each compound.

\section{Method Validation \\ Linearity}

The drug concentration versus peak area was plotted between $75-500 \mathrm{ng}^{\text {band }}{ }^{-1}(\mathrm{n}=3)$ to construct a standard curve of TQ (Figure 4). The graph was found to be linear, i.e., adherence to the system to Beer's law. The polynomial regression for the calibration plots showed the good linear relationship with the coefficient of correlation $r^{2}=0.997$ and regression equation $16.58 \mathrm{x}-224.2$ over the concentration range studied depicted in in Table 1 . There is no significant difference (ANOVA; $\mathrm{P}<0.05$ ) observed in the slopes of the standard curves in this range. The LOD and LOQ of the developed method were (18 and $54 \mathrm{ng}^{\text {band }}{ }^{-1}$ ) which showed that the method was sensitive to detect and quantitative the thymoquinone.

\section{Precision}

The intra-day and inter-day precision of TQ were expressed as \% recovery and percentage relative standard deviations (\% RSD) at three different levels were shown in Table 2. The percentage recovery for both was found to be in the range of $(98.5-99.7 \%)$ indicates the method was accurate by satisfying the acceptance criteria. The results for intra-day and inter-day variation of TQ recovery were studied at three different concentration levels 250, 350 and $400 \mathrm{ng}$ spot $^{-1}$. The $\%$ RSD value was found to be $<2 \%$ in all the cases. The low values of \% RSD are indicated the high precision of the method. 


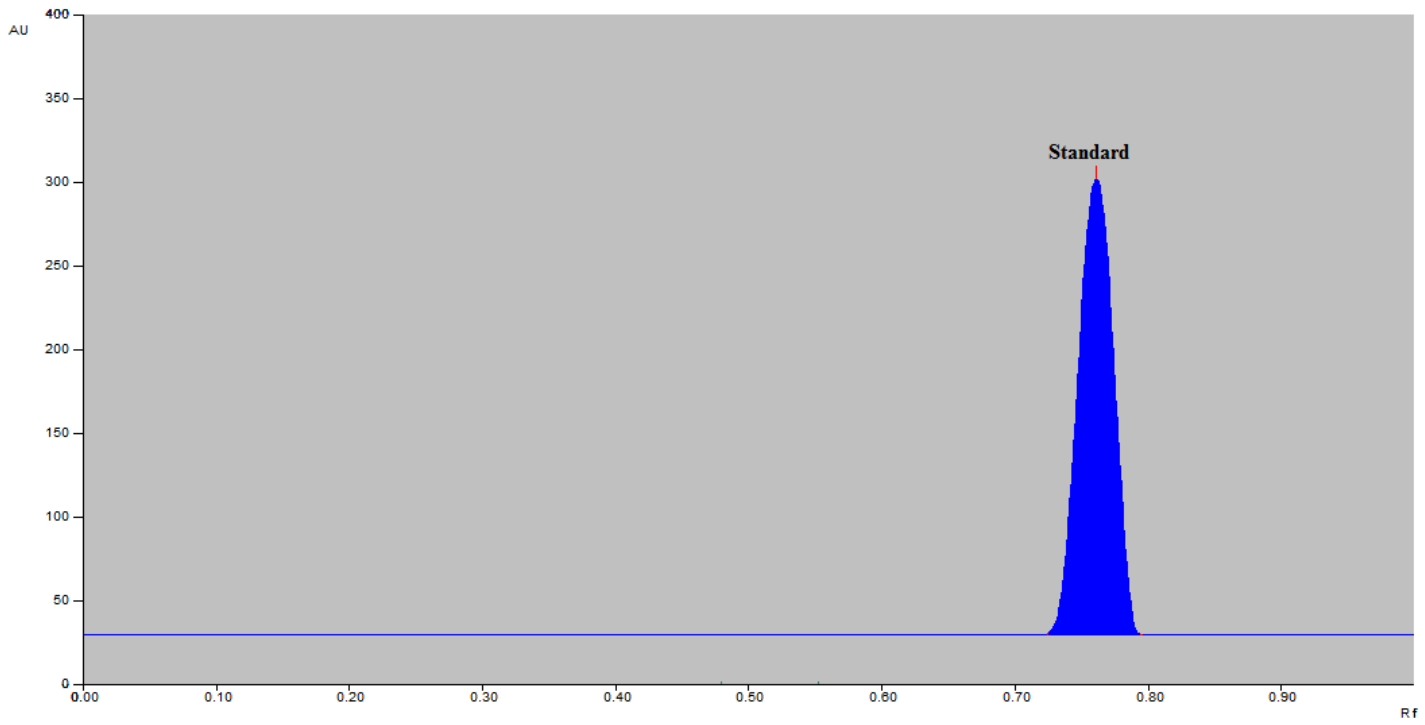

Figure 2: HPTLC chromatogram of standard thymoquinone $\left(R_{\mathrm{f}} 0.77\right)$.

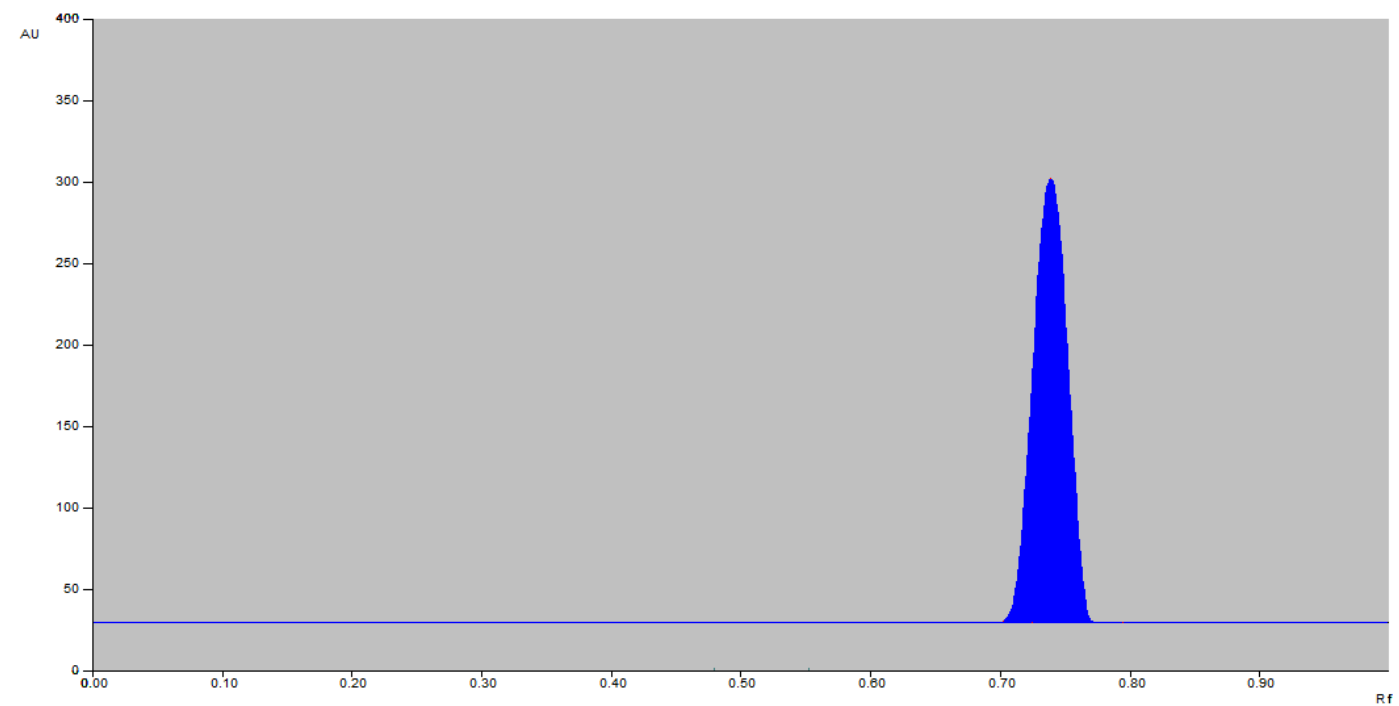

Figure 3: HPTLC chromatogram of thymoquinone extract $\left(\mathrm{R}_{\mathrm{f}} 0.77\right)$. 


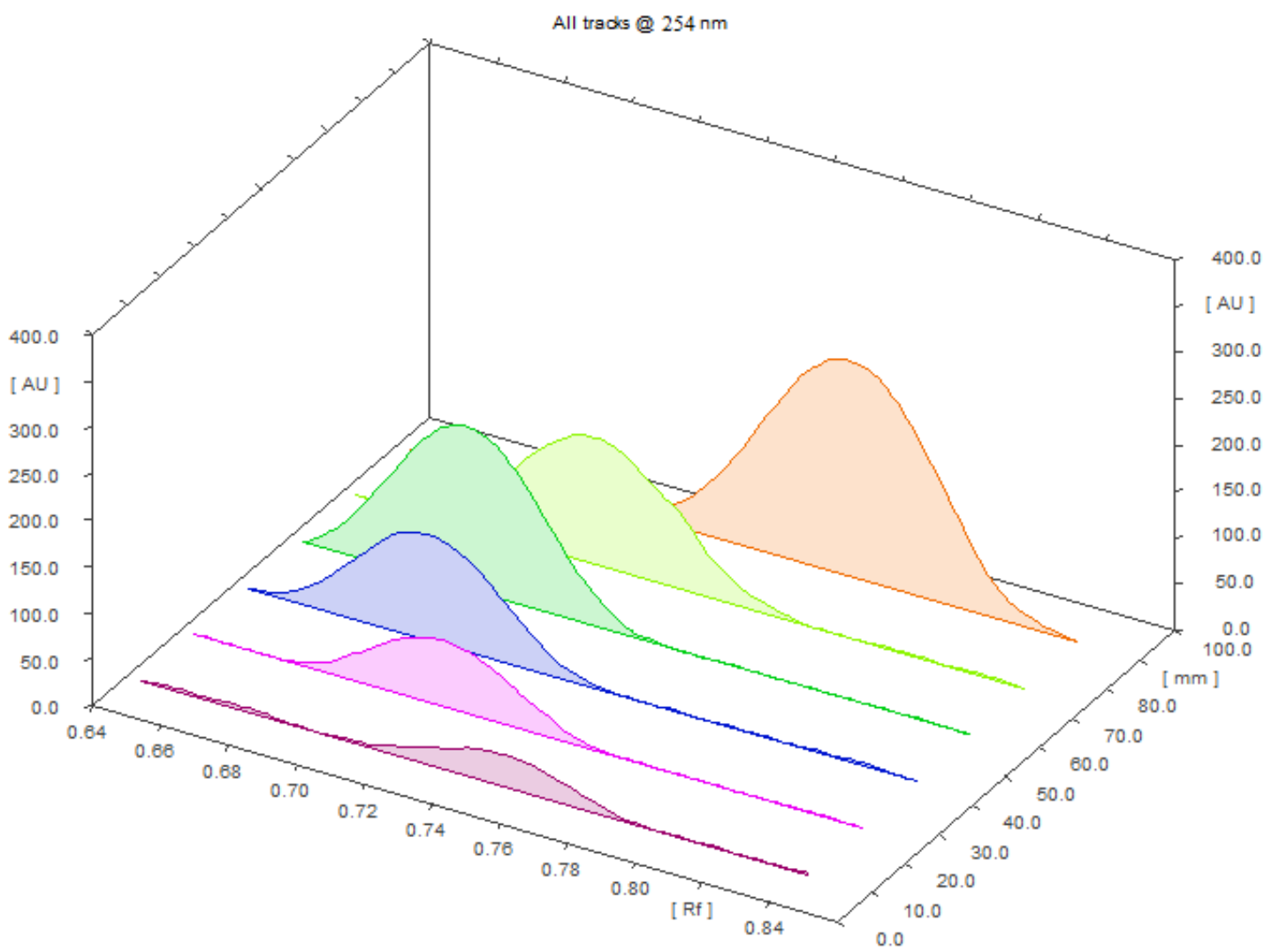

Figure 4: Comparative 3D scan of thymoquinone extract.
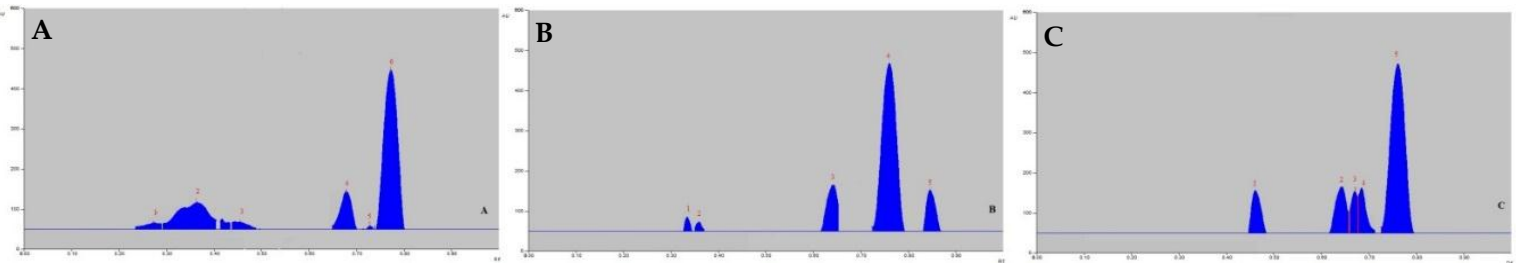

Figure 5: Degraded Chromatogram (A). $\mathrm{H}_{2} \mathrm{O}_{2}$ treated thymoquinone peak with degraded peak 1: degraded, $R_{f}$ : 0.29, peak 2, $R_{f}$. 0.36, peak 3: degraded, $R_{f} 0.46$, peak 4: degraded, $R_{f} .0 .68$, peak 5: degraded, $R_{f} .0 .73$ ); (B). dry heat and wet heat treated thymoquinone with degraded peak (peak 1: degraded, $R_{f}$ 0.33, peak 2, $R_{f}$. 0.36, peak 3: degraded, $R_{f} 0.64$, peak 4 : degraded, $R_{f}$. 0.85); (C). photochemical and uv rays treated thymoquinone with degraded peak (peak 1: Rf: 0.48, peak 2: Rf: 0.64, peak 3: Rf- 0.67, peak 3: Rf- 0.69). 
Table 2: Intra-day and Inter-day precision data of the Thymoquinone $(\mathrm{N}=6)$.

\begin{tabular}{|c|c|c|c|c|c|c|c|c|c|c|}
\hline \multirow{2}{*}{$\begin{array}{c}\text { Nominal } \\
\text { concentration }\end{array}$} & \multicolumn{5}{|c|}{ Intra-day batch } & \multicolumn{5}{|c|}{ Inter-day batch } \\
\hline & Final conc. & Precision & $\%$ Recovery & SD & $\% \mathrm{CV}$ & Final conc. & Precision & $\%$ Recovery & SD & $\% \mathrm{CV}$ \\
\hline 250 & 247.25 & 0.90 & 98.9 & 0.81 & 0.28 & 247.75 & 0.71 & 99.1 & 0.58 & 0.23 \\
\hline 350 & 348.25 & 0.37 & 99.5 & 0.67 & 0.19 & 344.75 & 0.20 & 98.5 & 0.29 & 0.08 \\
\hline 400 & 398.80 & 0.48 & 99.7 & 0.81 & 0.20 & 397.80 & 0.31 & 99.4 & 0.41 & 0.10 \\
\hline
\end{tabular}

SD-Standard Deviation, cv-Coefficient Variation

Table 3: Accuracy data of the Thymoquinone $(n=6)$.

\begin{tabular}{ccccccc}
\hline $\begin{array}{c}\text { Conc. added to } \\
\text { analyte (\%) }\end{array}$ & Theoretical (ng) & Added (ng) & Detected (ng) & Recovery (\%) & SD & \%CV \\
\hline 50 & \multirow{2}{*}{250} & 125 & 374.01 & 99.73 & 0.055 & 0.014 \\
100 & & 250 & 498.86 & 99.77 & 0.364 & 0.073 \\
150 & 375 & 623.95 & 99.83 & 0.756 & 0.121 \\
\hline
\end{tabular}

Accuracy $(\%)=[$ concentration found $) /($ nominal concentration $)] \times 100$

Table 4: Robustness of the developed HPTLC method of Thymoquinone $(n=6)$.

\begin{tabular}{|c|c|c|c|c|c|c|}
\hline \multicolumn{7}{|c|}{ Mobile Phase } \\
\hline \multirow{2}{*}{$\begin{array}{l}\text { Conc. } \\
\text { ng/ml }\end{array}$} & \multicolumn{2}{|c|}{ n-Hexane: ethyl acetate : methanol } & \multicolumn{4}{|c|}{ Results } \\
\hline & Original & Used & Area & SD & \%RSD & $\mathbf{R}_{\mathrm{f}}$ \\
\hline \multirow{3}{*}{350} & & $7.5: 1.8: 0.7$ & 154.83 & 1.24 & 0.80 & 0.75 \\
\hline & $(7: 2: 1)$ & $7: 2: 1$ & 156.86 & 1.40 & 0.90 & 0.77 \\
\hline & & 6.8:2.1:1.1 & 155.75 & 1.32 & 0.85 & 0.76 \\
\hline & \multicolumn{6}{|c|}{ Mobile Phase Volume $(15 \pm 2 \mathrm{ml})$} \\
\hline \multirow{2}{*}{$\begin{array}{l}\text { Conc. } \\
\text { ng/ml }\end{array}$} & \multirow{2}{*}{$\begin{array}{c}\text { Volume } \\
\text { (ml) }\end{array}$} & \multicolumn{4}{|c|}{ Result } & \\
\hline & & Area & SD & & & $\mathbf{R}_{\mathrm{f}}$ \\
\hline \multirow{3}{*}{350} & 17 & 156.83 & 1.39 & \multicolumn{2}{|c|}{0.89} & 0.78 \\
\hline & 15 & 155.86 & 1.49 & \multicolumn{2}{|c|}{0.96} & 0.77 \\
\hline & 13 & 157.75 & 1.73 & \multicolumn{2}{|c|}{1.1} & 0.76 \\
\hline & \multicolumn{6}{|c|}{ Duration of Saturation } \\
\hline \multirow{2}{*}{$\begin{array}{l}\text { Conc. } \\
\text { ng/ml }\end{array}$} & \multirow{2}{*}{$\begin{array}{l}\text { Time } \\
\text { (min) }\end{array}$} & \multicolumn{4}{|c|}{ Result } & \\
\hline & & Area & SD & & & $\mathbf{R}_{\mathrm{f}}$ \\
\hline \multirow{4}{*}{350} & 10 & 157.83 & 1.89 & \multicolumn{2}{|c|}{1.2} & 0.77 \\
\hline & 20 & 158.86 & 1.41 & \multicolumn{2}{|c|}{0.89} & 0.79 \\
\hline & 30 & 155.75 & 1.49 & \multicolumn{2}{|c|}{0.96} & 0.76 \\
\hline & \multicolumn{6}{|c|}{ Activated at $60 \pm 5^{\circ} \mathrm{C}$} \\
\hline \multirow{2}{*}{$\begin{array}{l}\text { Conc. } \\
\text { ng/ml }\end{array}$} & \multirow{2}{*}{$\begin{array}{l}\text { Time } \\
\text { (min) }\end{array}$} & \multicolumn{5}{|c|}{ Result } \\
\hline & & Area & SD & & & $\mathbf{R}_{\mathrm{f}}$ \\
\hline \multirow{3}{*}{350} & 2 & 155.83 & 1.21 & & & 0.78 \\
\hline & 5 & 156.86 & 1.28 & & & 0.77 \\
\hline & 7 & 154.75 & 1.47 & & & 0.76 \\
\hline
\end{tabular}




\section{Specificity}

The specificity of the method was ascertained by analyzing the pure TQ and methanolic extract. The spot for TQ in the sample was confirmed by comparing the Rf values and spectra of the spot with that of the standard. The peak purity of TQ was assessed by comparing the spectra at three different levels, i.e., peak start (S), peak apex (M) and peak end $(\mathrm{E})$ positions of the spot, i.e., $\mathrm{r}^{2}(\mathrm{~S}, \mathrm{M})=0.989$ and $\mathrm{r}^{2}(\mathrm{M}$, $\mathrm{E})=0.991$. A good correlation $\left(\mathrm{r}^{2}=0.997\right)$ was also obtained between standard and sample spectra of TQ, therefore, the method was considered specific.

\section{Accuracy}

The recoveries of the drugs were determined by standard addition method. The proposed method was used for extraction and subsequent estimation of TQ after spiking with 50,100 and $150 \%$ of the additional drug in the extract, and the afforded recovery was obtained 99.49 to $100.37 \%$ (Table 3). The result suggests that the method can be considered accurate, as the \%RSD of all the determinants were to be $<2 \%$ which indicated that the method was accurate and also there was no interference of the excipients present in tablets.

\section{Robustness}

Table 4 describes the robustness of the proposed method and their SD and \% RSD was calculated for the change in mobile phase composition, mobile phase volume, and duration of saturation and activation of prewashed-TLC plates at concentration levels of $350 \mathrm{ng} \mathrm{band}^{-1}$ (in triplicate). The result of the study showed that the small deliberate change in the chromatographic condition gives no significant effect on the area and $R_{f}$ value. The low values of \% RSD (less than 3) indicated the robustness of the developed method.

\section{Estimation of TQ in nanoformulation}

A single spot at $R_{f}=0.77 \pm 0.03$ was observed in the chromatogram of the TQ isolated from the extract along with other constituents. The presence of single spot confirms that there was no interference from the excipients found in the developed nanoformulation. The drug content was found to be $99.15 \pm 1.44$ with \% RSD of 0.0877 for nanoformulation for three replicate. The low value of \% RSD indicated the suitability of this method for routine analysis of TQ in pharmaceutical dosage forms.

\section{Stability studies}

The results of the forced degradation study of thymoquinone using are summarized in Table 5. Hydrogen peroxide-induced degradation. The sample degraded with $50 \% \mathrm{w} / \mathrm{v}$ hydrogen peroxide showed additional peaks at $R_{f}$ value of $0.29,0.36,0.46,0.68$ and 0.73 (Figure 5A). The spots of degraded products were well resolved from the parent compound spot.

\section{Dry heat and wet heat degradation}

The samples degraded under dry heat and wet heat conditions showed additional peaks at $\mathrm{R}_{\mathrm{f}}$ values of $0.33,0.36,0.64$ and 0.85 , respectively (Figure 5B). The spots of degraded products were well resolved from the parent compound spot.

\section{Photochemical and UV degradation}

The photodegraded sample showed one additional peak at $R_{f}$ value of $0.48,0.64$, and 0.67 (Figure $5 C$ ) when thymoquinone solution was left in daylight for 3 days. The
Table 5: Stress induced stability studies data for the developed method.

\begin{tabular}{ccc}
\hline $\begin{array}{c}\text { Degradation } \\
\text { condition }\end{array}$ & $\begin{array}{c}\text { No. of degradation } \\
\text { products }\end{array}$ & $\boldsymbol{R}_{f}$ value \\
\hline $\begin{array}{c}\text { Peroxide-induced } \\
\text { degradation }\end{array}$ & 3 & $0.38,0.40,0.45$ \\
Dry heat-wet heat & & $0.50,0.55$, \\
$\left(100^{\circ} \mathrm{C}\right)$ & 4 & $0.64,0.69$ \\
Photochemical & 1 & 0.74 \\
degradation & 1 & 0.79 \\
UV degradation & & \\
\hline
\end{tabular}

thymoquinone was degraded when exposed to UV irradiation for 15 days and showed additional peaks at $R_{f}$ value of 0.69 . The spot of UV degraded product was well resolved from the standard.

\section{CONCLUSION}

HPTLC is a simple, rapid and accurate method for analyzing plant material. This method can be used for phytochemical profiling of plants and quantification of compounds present in plants, with increasing demand for herbal products as medicines and cosmetics there is an urgent need for standardization of plant products. The presented study clearly gave evidennce of the bioactive thymoquinone in methanolic extracts of Nigella Sativa. The developed method is simple, precise, specific, sensitive, and accurate. Further, this method can be effectively used for routine quality control of herbal materials as well as formulations containing this compound.

\section{CONFLICT OF INTEREST}

None.

\section{ACKNOWLEDGEMENT}

Thanks to Mr. Manish (Sunpure Extract Pvt. Ltd. Delhi) for providing the herbal sample for the analysis study.

\section{REFERENCES}

AbouBasha, L., Rashed, M.S., Aboul-Enein, H.Y. (1995). TLC assay of thymoquinone in black seed oil (Nigella sativa Linn) and identification of dithymoquinone and thymol. J Liq Chromatogr Relat Technol 18: 105-115. [DOI]

Akhtar, M., Imam, S.S., Ahmad, M.A., Najmi, A.K., Mujeeb, M., and Aqil, M., (2014). Neuroprotective study of Nigella sativa-loaded oral provesicular lipid formulation: in vitro and ex vivo study. Drug Deliv, 21(6): 487-494. [DOI]

Alam, P., Yusufoglu, H., Alam, A. (2013). HPTLC densitometric method for analysis of thymoquinone in Nigella sativa extracts and marketed formulations Asian Pac. J. Trop Dis.; 3(6): 467-471. [DOI]

Ali, B.H., Blunden, G., (2003). Pharmacological and toxicological properties of Nigella sativa. Phytother Res 17: 299-305. [DOI]

Ali, S., Taleuzzaman, M., Gilani, S.J., Ahmed, M.L., and Hafeez, A., (2016). Quantitative estimation of Donepenzil hydrochloride tablet by HPLC.IJPC 06 (02)

Bakshi, M., Singh, S., (2011). Development of validated stability-indicating assay methods--critical review. J. Pharm. Biomed. Anal. 28 1011-1040. [DOI]

Dixit, R.P., Barhate, C.R., Nagarsenker, M.S. (2008). Stability-indicating HPTLC method for simultaneous determination of ezetimibe and simvastatin. Chromatographia 67: 101-107. [DOI]

Ghosheh, O.A., Houdi, A.A., Crooks, P.A., (1999). High performance liquid chromatographic analysis of the pharmacologically active quinones and related compounds in the oil of the black seed (Nigella sativa L.). Pharm Biomed Anal 19: 757-762. [DOI] 
Ghosheh,O.A., Houdi,A.A., Crooks,P.A., (1999). High performance liquid chromatographicanalysis of the pharmacologically active quinones and related compounds in the oil of the black seed (Nigella sativa L.). J Pharm Biomed Anal 19: 757-762. [DOI]

Houghton, P.J., Zarka, R., DelasHeras, B., Hoult, J.R. (1995). Fixed oil of Nigella sativa and derived thymoquinone inhibit eicosanoid generation in leukocytes and membrane lipid peroxidation. Planta Med 61: 33-36. [DOI]

ICH, Q1A (October1993). Stability Testing of New Drug Substances and Products, International Council for Harmonisation, Geneva.

ICH, Q2A, (October 1994). Validation of Analytical Procedure: Methodology, International Council for Harmonisation, Geneva,

Kaur, A.D., Ravichandran, V., Jain, P.K., Agrawal, R.K., (2008). High-performance thin layer chromatography method for estimation of conessine in herbal extract and pharmaceutical dosage formulations. J Pharm Biomed Anal 46: 391-394. [DOI]

Michelitsch, A., Rittmannsberger, A. (2003). A simple differential pulsepolarographic method for the determination of thymoquinone in black seed oil. Phytochem Anal 14: 224-227. [DOI]

Mittal, A., Imam, S.S., Parmar, S., Gilani, S.J. and Taleuzzaman, M., (2015) Design of Experiment based Optimized RP-HPLC Method for Simultaneous Estimation of Amlodipine and Valsartan in Bulk and Tablet Formulations. Austin J Anal Pharm Chem, 2(6): 1-6.

Ranganathan, T.V., Kulkarni, R.P., (2002). Food Chemist. A simple method for the analysis of trehalose using HPTLC. 77 263-265.
Reelma, M., Pereira, V, Chandrashekhar, R, Barhate, R., Kulkarni, G., Jagtapa, A., (2011). Validated High-performance Thin-layer

Chromatographic Method for the Quantification of Thymoquinone in Nigella Sativa Extracts and Formulations. Phytochem. Anal., 22, 367-373. [DOI]

Sayeed, S., Imam, S. S., Najmi, A.K., Aqil, M., and Akhtar, M., (2017), Nonionic surfactant based thymoquinone loaded nanoproniosomal formulation: invitro physicochemical evaluation and in vivo

hepatoprotective efficacy. Drug Development and Industrial Pharmacy, 43, 9, 1413-1420. [DOI]

Sethi, P.D., (1996) High Performance Thin Layer Chromatography, Quantitative Analysis of Pharmaceutical Formulations, CBS Publishers, New Delhi, India.

Stolarczyk, M., Maalanka, A., Apola, A., Krzek, J., (2010). Analysis of hypotensive compounds occurring in complex agents Acta Pol. Pharm.Drug Res. 67 441-454.

Tayade, N.G., Nagarsenker, M.S. (2007). Validated HPTLC method of analysis for artemether and its formulations. J Pharm Biomed Anal 43: 839844. [DOI]

Zammataro, A., Saletti, R., Civiale, C., Muccilli, V., Cunsolo, V., Foti, S., (2010) Simultaneous quantification of carteolol and dorzolamide in rabbit aqueous humor and ciliary body by liquid chromatography/atmospheric pressure chemical ionization mass spectrometry. J Chromatogr B Analyt Technol Biomed Life Sci.; 878 (910):807-14. [DOI] 